\title{
New guidelines: do we have all the answers
}

\section{- Petra Grubić Rotkvić1 ${ }^{*}$, (1) Jozica Šikić ${ }^{1,2}$, - Edvard Galić1,2, (1) Jasna Čerkez Habek ${ }^{1,3}$, \\ ¿lorinka Planinić ${ }^{1}$}

'University Hospital „Sveti Duh“, Zagreb, Croatia ${ }^{2}$ University of Zagreb School of Medicine, Zagreb, Croatia ${ }^{3}$ Croatian Catholic University, Zagreb, Croatia
KEYWORDS: mitral regurgitation, assessment of left ventricle dysfunction. CITATION: Cardiol Croat. 2018;13(5-6):204. | https://doi.org/10.15836/ccar2018.204

*ADDRESS FOR CORRESPONDENCE: Petra Grubić Rotkvić, Klinička bolnica „Sveti Duh“, Sv. Duh 64, HR-10000 Zagreb, Croatia. / E-mail: petra.grubic84@gmail.com

ORCID: Petra Grubić Rotkvić, https://orcid.org/0000-0002-2587-1932 • Jozica Šikić, https://orcid.org/0000-0003-4488-0559 Edvard Galić, https://orcid.org/0000-0002-5707-0961 • Jasna Čerkez Habek, https://orcid.org/0000-0003-3177-3797 Zrinka Planinić, https://orcid.org/0000-0001-8664-3338

\section{|I||||||||||||||||||||||||||||||||||||||||||||||||||||||||||||||||||||||||||||||||||||||||||||||||||||||||||||||||||||||||||||||||}

Background: Appropriate timing of surgery in asymptomatic severe primary mitral regurgitation (MR) remains challenging. According to the guidelines, surgery is recommended for patients with symptomatic severe primary MR or those with asymptomatic left ventricular (LV) systolic dysfunction, newonset atrial fibrillation and pulmonary arterial hypertension ${ }^{1}$.
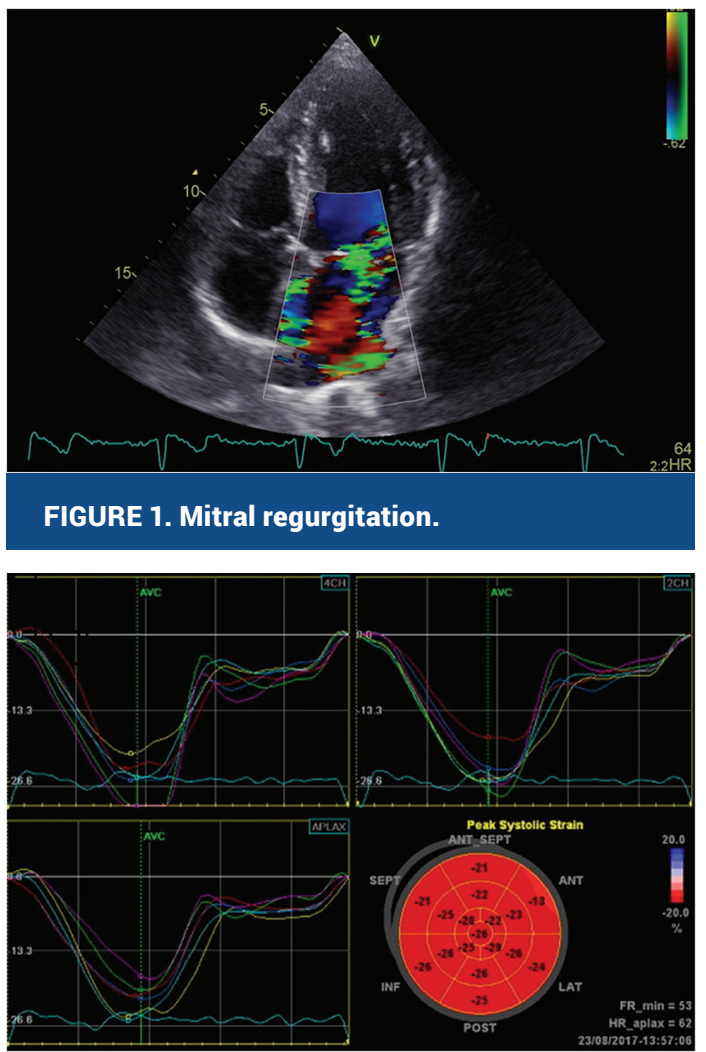

FIGURE 2. Strain analysis.

Case report: 40-year-old male came to our Echo Lab because of a heart murmur. He had no previous health problems and no disturbances in his daily activities. Myxomatous mitral valve degeneration with prolapse of the posterior leaflet and severe MR was found (Figure 1). No additional echo findings that would indicate surgical intervention were detected (LVESD was 34 mm, LVEF 65\%, RVSP 30 mmHg, no significant LA enlargement). He was in sinus rhythm. We also measured left ventricular global longitudinal strain (LV-GLS) and preformed an exercise stress testing to assess his functional capacity with addition of echocardiographic measurement of RVSP during peak stress. He achieved $100 \%$ of predicted METs with no worsening of RVSP and LV-GLS was -24\% (Figure 2). Based on the above-mentioned findings, we decided to follow-up the patient.

Discussion: Clinicians and patients often choose to postpone valve surgery as long as justified. This "watchful waiting" approach is dictated by a timely identification of LV dysfunction. Ejection fraction and end-systolic dimensions are affected by the altered loading conditions in MR and can remain falsely normal despite underlying myocardial dysfunction ${ }^{2}$. New parameters capable of detecting onset of LV dysfunction earlier could help discriminate the higher risk patients. Current European guidelines state that the use of LV-GLS could be of potential interest and determination of functional capacity may be useful, but there are no exact recommendations ${ }^{3}$. In the study of Mentias et al., reduced exercise capacity and worsening LVGLS were associated with mortality providing additive prognostic utility ${ }^{1}$ Maybe the detection of the relative change of GLS from baseline rather than an absolute cut-off value as in cardio-oncology could be helpful.

Conclusion: We are still looking for an optimal timepoint when we should operate patients with asymptomatic severe primary MR. Further investigations are required.

\section{RECEIVED:}

May 2, 2018

ACCEPTED:

May 10, 2018

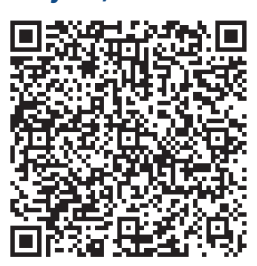

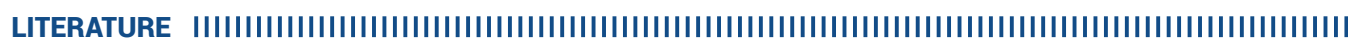

1. Mentias A, Naji P, Gillinov AM, Rodriguez LL, Reed G, Mihaljevic T, et al. Strain Echocardiography and Functional Capacity in Asymptomatic Primary Mitral Regurgitation With Preserved Ejection Fraction. J Am Coll Cardiol. 2016 Nov 1;68(18):1974-1986. https://doi.org/10.1016/j.jacc.2016.08.030

2. Bertrand PB, Vandervoort PM. Subclinical Myocardial Dysfunction in Asymptomatic Mitral Regurgitation: "Watchful Waiting 2.0". J Am Coll Cardiol. 2016 Nov 1;68(18):1987-1989. https://doi.org/10.1016/j.jacc.2016.08.029

3. Baumgartner H, Falk V, Bax JJ, De Bonis M, Hamm C, Holm PJ, et al; ESC Scientific Document Group. 2017 ESC/EACTS Guidelines for the management of valvular heart disease. Eur Heart J. 2017 Sep 21:38(36):2739-2791. https://doi.org/10.1093/eurheartj/ehx391 $\square$ Cardiologia Croatica 2018;13(5-6):204. 